\title{
Factors Preventing the Successful Implementation of Information Systems: Case of the Elementary Public Education in Mexico
}

\author{
Israel Patiño ${ }^{1, *}$ \\ ${ }^{1}$ Division of Accounting and Administration, Technologic for Higher Studies of Ecatepec, Mexico \\ *Correspondence: Technological Av S/N, Valle of Anahuac, Ecatepec of Morelos, State of Mexico, CP. 55210, \\ Mexico. Tel: 1-55-5000-2304. E-mail: ispa_ga@hotmail.com
}

Received: June 10, 2015

Accepted: July 14, $2015 \quad$ Online Published: August 15, 2015

doi:10.5430/wje.v5n4p93

URL: http://dx.doi.org/10.5430/wje.v5n4p93

\begin{abstract}
This paper aims to identify the factors that impede the successful implementation of information systems in the case of primary public education for the systematization of administrative and operational processes. Once identified and diagnosed the cause, the proposal is made, in order to ensure that implementation. This aided with scientific methodologies such as inductive, systemic structural functional, besides the application of field research and data collection and generation of theoretical and contextual framework of public primary education. From the above, resulted in the implementation of systems must be accompanied by the context factors in which it will be implemented, as it is training, raising educational levels, encourage feedback from stakeholders, among others things
\end{abstract}

Keywords: Factors, Information Systems, Public Primary Education

\section{Introduction}

This article consists of four sections, the first of which seeks to contextualize public primary education in Mexico, since Pre Hispanic era, colonial, post-revolutionary and independent of Mexico. Subsequently presents a summary of the contextualization of information systems, in addition are contemplated the methodology of scientific research to support this investigation. Finally, a diagnosis is generated and derived from that, be create an proposed in order to support the implementation of information systems, in order to systematize the administrative and operational processes in public schools primaries and thus facilitate their retention and evolution to a short, medium and long term. Hence the proposal is an alternative to ensure successful implementation of such systems.

\section{History of Public Education in Mexico}

\subsection{Education in the Era Pre Hispánica}

Was systematic, complex and rigorous process by which societies prepare their children and teenagers for to performance into adulthood were very ancient in Mesoamerica. Schools were not just centers of education, as now are conceived. Among the Mexica schools were mainly species of temples, religious institutions that focused on children and youth for the service, the children went to work and also to educate. Several school classes are mentioned in documentary sources. The calmecac ("place of the row of houses") was intended for the nobility, though not exclusively. The telpochcalli ("youth house") was the school they were almost all commoners. There were seven calmerac citywide; instead the telpochcalli were very numerous, it is said that there were ten or fifteen in each neighborhood. Female school ichpachcalli ("house maids") is possible that they were more of them, dedicated to different gods (Escalante, 1985)

\subsection{Education in Mexico in the Colonial Era}

With the arrival of the first missionaries to New Spain, the various religious orders took the training and education, initiatives to create educational institutions born of the need to train new priests and expand evangelism. It is for this reason that the church took such an important role in education. However, the religious orders had not intended to consolidate a formal education system, only educate and train new local elites. For nearly three centuries, until shortly after the culmination of Independence, the religious educational model relied heavily on Kant's doctrine, 
which established based on discipline as the central idea of the educational process instruction, represented a process of substitution or elimination of concepts and mental categories of the Hispanic cultures by new schemes and lifestyles more convenient to the Spanish culture (Castrejon, 1986).

Moreover, public education is one of the duties of every enlightened government and only the despots and tyrants claim ignorance of the people to more easily abuse their rights (Ramos, 1973). The educational rights are embodied in the Constitution issued by the Cortes of Cadiz in 1812 Curated in New Spain in September and later suspended and restored (twice) left in the hands of municipalities care elementary and noted as one of the duties of the councils promote education, in Article 366 of Title IX.

\subsection{Education in the Age of Independent Mexico}

The Federal Constitution of the Mexican United States of 1824 stood alone as power of government, through Congress, set all kinds of educational institutions. It stated that the same right should the state legislatures, but nothing about elementary education. Hence both the lack of resources prevented any state action. This topic remains in the hands of the Lancastrian Company, founded in Mexico on February 22, 1822 and federal and state aid, the country was founded in elementary and normal schools. In 1867 the Organic Law of Education was promulgated, in her free and compulsory primary education was established, it precluded all curriculum and religious education contained provisions for secondary education, under the principles of positivism (Meneses, 1998). The school of Preparatory Studies laid the foundation of professional education. The law only applied to the Federal District and the federal territories, but exerted influence over state laws. During the Porfiriato, Joaquín Baranda, Minister of Justice and Instruction, convened two conferences where educators, teachers, intellectuals and authorities met. The results of these conferences helped define a new government project of public education, which was consolidated with the promulgation of the Compulsory Education Act 1888. With the arrival of Justo Sierra to the Undersecretary of Public Instruction in 1901 opened a new period in the history of Mexican education system (Martinez, 1992). At this time the Department of Public Instruction and Fine Arts was established, which Justo Sierra was the first owner in 1905 ?

\subsection{Education in Post-Revolutionary Era}

During the revolutionary period, the forming process of the Mexican educational system had a significant setback, however, at the end of this period, with the promulgation of the Constitution of the Mexican United States of 1917, was first awarded to the constitutional right of every Mexican citizen has to receive a secular, compulsory and free education (Monroy, 1975). Also, higher educational powers to the State to coordinate and monitor the operation of public and private schools were awarded, unfortunately, with the abolition of the Ministry of Public Instruction and Fine Arts given by the Constituent Congress. The presence of various factors such as the existence of scattered rural settlements throughout the territory, the chronic lack of budgetary resources, heterogeneity in the ways each state and municipality attending their duties and a highly reduced magisterial plant, exacerbated this situation. The creation of the Ministry of Public Education (SEP) in September 1921, was a decisive event, to change this situation, facilitated the concurrent action of the federal government directly throughout the country. With this, it was possible to balance a little uneven attention afforded to state and local education services. José Vasconcelos, the first holder of this institution, made a new educational system to meet the needs of education and academic training of all social sectors (Iturriaga, 1981). One of the most important contributions of management Vasconcelos was rural education: elementary schools and some rural normal schools were created, and cultural and technical missions, educational groups, professionals who addressed various rural locations to train teachers and work were formed in favor of the community.

\subsection{Education in the Modern Era in Mexico}

Basic education in Mexico has had several transformations in its time responding to specific contexts and needs. One of the most important (prior to 1992) was to achieve universal primary education, an educational policy characterized by focused coverage, based on the principles of the Free Mexican Constitution, such as secularism, and democratic basic education and the right of all individuals to receive education (Lopez, 2007). Then in May 1992 the National Agreement for the Modernization of Basic Education (NAMBE) is carried out a redistribution of the functions of the federal government and state governments in relation to the operation of services of preschool primary and secondary, which mostly happen to be administered by the state governments, besides obtaining powers to meet the construction, rehabilitation and equipping of schools. The Federation for his part, agreed to transfer sufficient resources of state governments for the management of primary schools. In 1993, in addition to the decentralization process triggered by the signing of NAMBE, the obligation for the State to provide secondary education through the amendment of Article 3rd set. Constitutional (Profile of Education in Mexico, 2000), and in 2002 the reform becomes compulsory 
preschool education are made. With these reforms, educational policies in Mexico focused on the coverage, which to date have made significant progress, as well as indicators of efficiency, failure, and dropout rates in basic education. However, the globalization of education and the knowledge economy, revealed a new approach to evaluate the progress of education, quality of education, measured by student learning, which focuses indicator of education policy today, finally the last update that protects in the constitutional primary public education in Mexico in the Clause 3., Fraction I to VIII, which gives the following, (Chamber of Deputies of the Congress of the Union, 2010). Article 3 of the Constitution of the Mexican United States says the letter as follows: "Everyone has the right to an education. The State-Federation, States, Federal District and Municipalities, provide preschool and secondary education, primary, preschool and school, primary secondary made compulsory basic education. The education provided by the state tend to develop harmoniously all the faculties of man and promote him, at once, the love of country and an awareness of international solidarity, independence and justice, "Fractions I to VIII".

\section{Method}

\subsection{Type of Research}

By the characteristics of this research, the following types of scientific research were contemplated:

Descriptive, this type of research is the characterization of a fact, phenomenon, individual or group, in order to establish its structure or behavior (Fernandez, Narez, \& Garcia, 2008).

Explanatory, is responsible for searching the reason of the facts by establishing cause-effect relationships.

Field research is the main technique is employing the survey. The Survey is a technique for acquiring information of sociological interest, using a questionnaire previously developed (Hernandez, Fernandez, \& Baptista, 1997).

\subsection{Research Methodology}

It is important to consider in scientific research and technological development, the methodology to be used at the beginning and in the course of the investigation as this guide and delimit the proposal is intended. Furthermore this methodology should consider the findings that are generated during research for the purpose of founding and endorsed research. The research methodology provides the methods and procedures for scientific-research activity with quality. The methods are the access to sources, hence the importance of their selection and use. In the case of this research the following research methods are distinguished:

- Structural Systemic Functional Method, indicate the following: this type of method is used in structures and systems. Its action is evident in the interplay of ideas, connecting concepts, recommendations and systems modeling, methodologies and strategies (Fernandez et al., 2008).

- Inductive. Is the reasoning from the knowledge that the characters needed or necessary connection of objects in a class (Castillo de la Peña, 2010).

\section{Context of the Information Systems}

\subsection{Clasification of the Information Systems}

Information systems, are a formal set of processes that operate on a collection of data structured according to the needs of the company, which collect, process and distribute information selectively required for operation the company and management activities and corresponding control, supporting, at least in part, the decision-making processes necessary to perform business functions of the company in accordance with its strategy (Andreu \& Value, 1991).

Next, the types of information systems are (García, 2000).

Types of Information Systems:

- Degree of formality: Formal, Informal, Automation, Manuals, Computer

- Relationship decision: Strategic (top management), Management (intermediate), Operating (operational control)

- Functionality: Business, Accounting, Financial Management, Human Resources, Production

- Degree Specialization: Specific and general

On the other hand, provide the following classification of information systems (K. Laudon \& J. Laundon, 1996): 
- Processing System Operations (PSO): computer systems responsible for the administration of those daily routine operations necessary in business management (payroll applications, order tracking, auditing and logging and employee data).

- Knowledge Work Systems (KWS): those in charge of information systems to support organizations that handle the creation and integration of new knowledge for the company (workstations Management); part of the knowledge level.

- Automation in the Office (AO): Text processor, notebook, spreadsheets, email) systems used to increase the productivity of employees who handle information at the lower levels of the organization; are framed in the level of knowledge as the Knowledge Work Systems.

- Information Systems Management (ISM): information systems management level employees in the process of planning, control and decision making by providing reports on ordinary activities (inventory control, annual budgets, analyzing investment decisions and funding).

- Systems for Decision Support (SDS): interactive computer systems that help different users in the decision making process, when using different data and models to solve unstructured problems (cost analysis, analysis price and profit, sales analysis by geographic area).

- Management Support Systems (MSS): information systems at the strategic level of the organization designed to make strategic decisions through the use of graphics and advanced communications.

\subsection{Evolution of the Information Systems}

The information Systems have evolved over the years to be called strategic information systems, first as part of support for the activities of the companies. With the development of information technology and telecommunications, information systems evolved with increased effectiveness and efficiency in tasks such as save time in the development of activities and store as much information in the smallest possible space, improve security along with database and eliminate human errors. The evolution of information systems based on the evolution of information technology. To the extent that computer equipment, software, hardware, databases, telecommunications and information systems were becoming more important in organizations being started to be considered as an element of the planning process were developed, as indicated in Table 1 (Gibson \& Nolan, 1974).

Table 1. Evolution of the Information Systems

\begin{tabular}{|c|c|}
\hline $\begin{array}{l}\text { Stages of development of } \\
\text { information systems }\end{array}$ & Characteristics \\
\hline & $\begin{array}{l}\text { - Introduction of information technology in the enterprise } \\
\text { - informatics Applications to mechanize and automate routine processes }\end{array}$ \\
\hline 1. Initiation & - Menor gasto en tecnología de la información y la deficiente capacitación del personal \\
\hline 2. Contagion & $\begin{array}{l}\text { - The application of information technologies originate spectacular results } \\
\text { - Dissemination of information technologies in all areas of the company } \\
\text { - Increases staff qualifications } \\
\text { - There is a great lack of coordination and poor planning in the development of } \\
\text { information systems }\end{array}$ \\
\hline 3 Control & $\begin{array}{l}\text { - Top management of the organization is concerned with information systems because of } \\
\text { the high cost them }\end{array}$ \\
\hline 4. Integration & $\begin{array}{l}\text { - Increased spending is controlled } \\
\text { - The integration of existing information systems occurs in different areas of the company } \\
\text { - Improve and refine information systems }\end{array}$ \\
\hline 5. Management of the information & $\begin{array}{l}\text { - The information system acquires a strategic dimension in the business } \\
\text { - Decentralization of certain applications }\end{array}$ \\
\hline 6. Maturity & $\begin{array}{l}\text { - Development of information systems at higher levels of the organization appearing in } \\
\text { Strategic of Information Systems } \\
\text { - Becomes very important creativity and innovation }\end{array}$ \\
\hline
\end{tabular}

Source: Managing the four stages of EDP Growth, p. 78 (Gibson \& Nolan, 1974) 


\subsection{Process of Incorporation of the Information Systems}

In any process of incorporation of information systems (IS), is conducive to the development of new production and organizational structures as well as new strategic and management models (Montoya \& Schmidt, 1997). In this process, information systems develop again a key role as a source of information collection and generation is one of the best means to approach the environment and develop a deep understanding of the different actors that comprise it (Llien \& Rangaswamy, 1997). According to this perspective, organizations begin to develop processes based on the use of the SI, and oriented to the collection and generation of knowledge systems. Moreover, in a simple, quick and inexpensive way, the SI allows access by an entity to a lot of relevant and current information (Argyres, 1999). Similarly, the use of IS facilitates the acquisition, analysis and storage of information and its conversion into knowledge and its dissemination over all entities, as part of the incorporation process. Thus the IS, in addition to acting as a source and transmitter of information and knowledge, also a socializing element (Dyer \& Nebeoka, 2000), (Leenders \& Wierenga, 2002) and (Rotwell, 1994).

The process of incorporating information systems is as follows (Montaño, 2008):

1. Preparing the environment. The preparation of the environment involves two preliminary events, one to define the scenario where the change (organizational culture) will be held and another to define the strategic management process through the creation of a responsible unit.

2. Sensitization of Innovation. The initial phase of this process includes the socialization of current topics. This phase is disclosed to those involved (academic units, principals and teachers) the objectives sought with the use of IT.

3. Exploration Technology Resources. The exploration phase of technological resources may be called "Directed Test Phase", which means looking for the effective use of technology resources, creating technical and user manuals, and use of available resources.

4. Exploration Educational Resource. The focus of this phase is focused on the development of training, which incorporates the active participation of stakeholders (administrative, operational and citizens).

5. Generating proposals or prototypes. This phase is to establish IS proposals that involve project work, collecting resources and with technological training, previously evaluated in the previous stages, allowing reuse and adaptation, through specific projects.

6. Feedback. This phase is aimed at the interaction between information systems and operators the same incentive to make suggestions for improvement or technology upgrades.

\section{Results}

Once contextualized the primary public education, the information systems and explained the scientific methodology is presented below which are the results of the investigation. While it is difficult to determine, what factors are that impede the successful implementation of information systems are presented below, the factors for consideration by the author, in the case of primary education published in Mexico, according to Figure 1. 


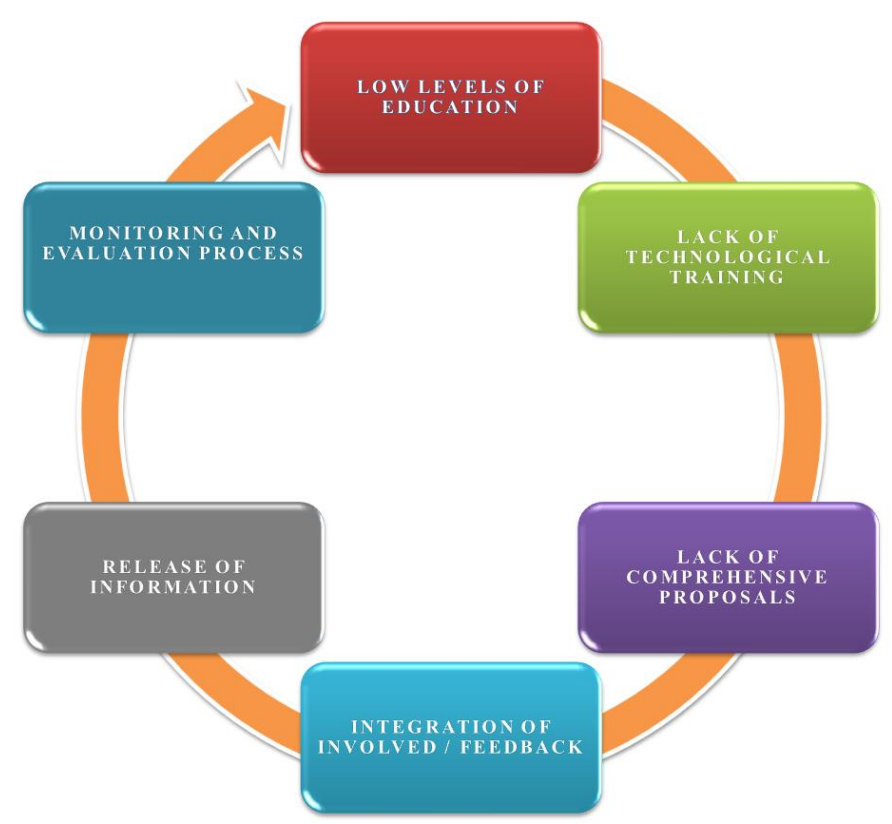

Figure 1. Factors Impeding the Successful Implementation of Information Systems in Public Primary Education in Mexico

Source: own

Low levels of education. Education is not only an important factor in this research, however for purposes of this, the raise educational levels, could increase the creation and application of new technologies and information systems to systematize the administrative and operational processes. These levels of education should be in the case of teachers, parents, who are having a direct interaction with the use of technology and therefore the transmission of that knowledge. Presented below are the educational levels of teachers in public elementary schools, according to Graphic 1 and the parents as shown in Graphic 2, presented below study levels of these groups and terminal efficiency of elementary students.

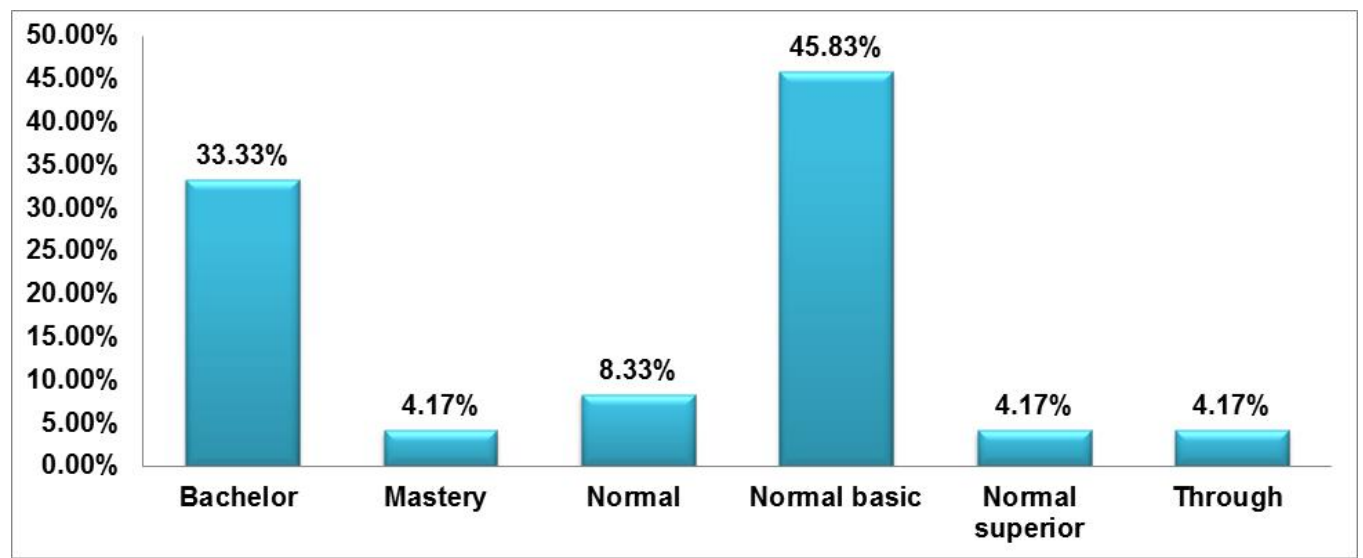

Graphic 1. Educational Levels of Teachers in Public Primary Schools in the Municipality of Ecatepec de Morelos State Mexico

Source: own, from field studies conducted in the municipality of Ecatepec de Morelos, State of Mexico 


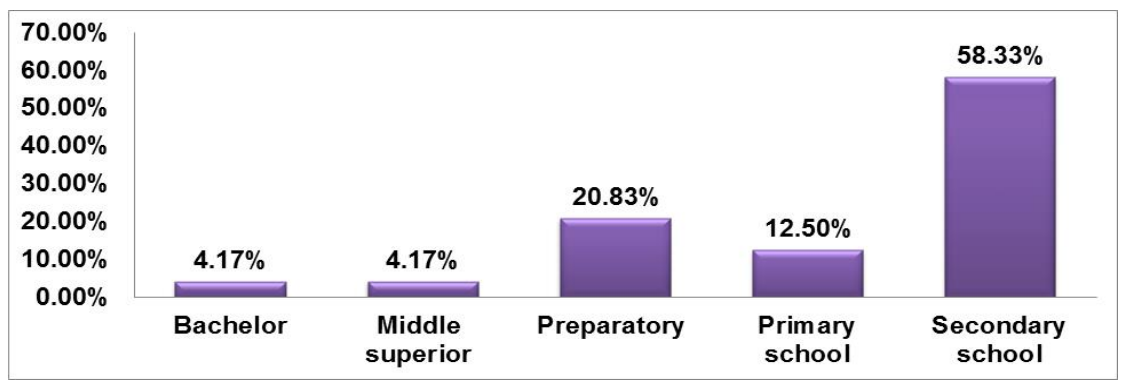

Graphic 2. Educational Levels of Parents/Guardians in Public Primary Schools in the Municipality of Ecatepec de Morelos State Mexico

Source: own, from field studies conducted in the municipality of Ecatepec de Morelos, State of Mexico

On the other hand are presented below in Grapchic 3, the average attendance of the population higher to 3 years, in public elementary schools (1st to 6th grade approved) and the municipality of Ecatepec.

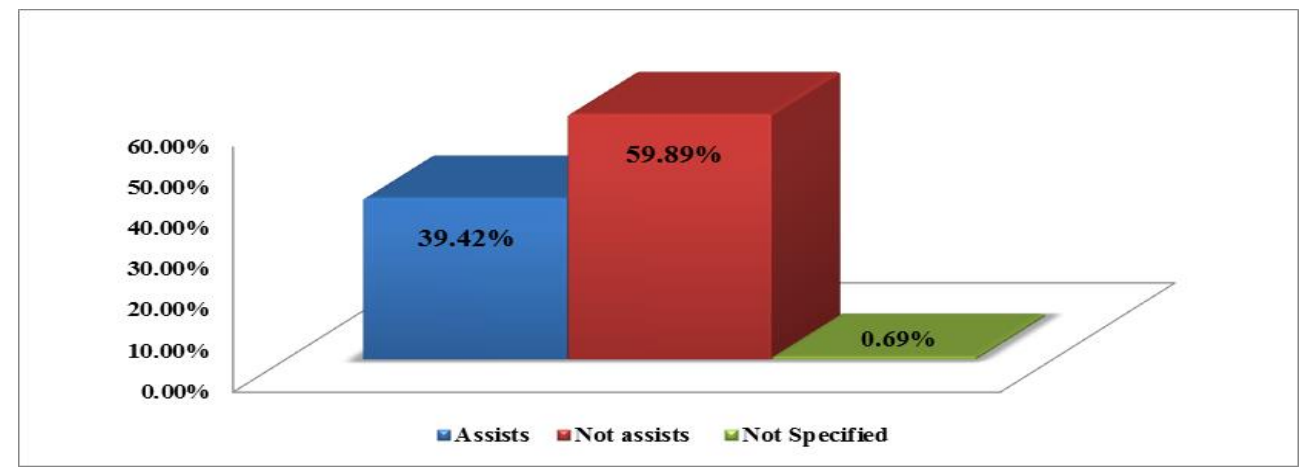

Graphic 3. Percentage of Assistance of Population in Public Elementary Schools with Approved Grades

Source: own, from the data presented in the INEGI (2010), http://www3.inegi.org.mx/sistemas/tabuladosbasicos/default.aspx?c=27302\&s=est

Lack of technological training. The education authorities have implemented several programs of teacher training, however it is important to continue to promote this type of activity, so technological training in the specific case of information systems is vital to generate knowledge, ideas to encourage their appropriate use, development and successful implementation. Are presented below in Graphic 4, the periodicity in the technology training for teachers in public primary schools, in the town of Ecatepec de Morelos, State of Mexico

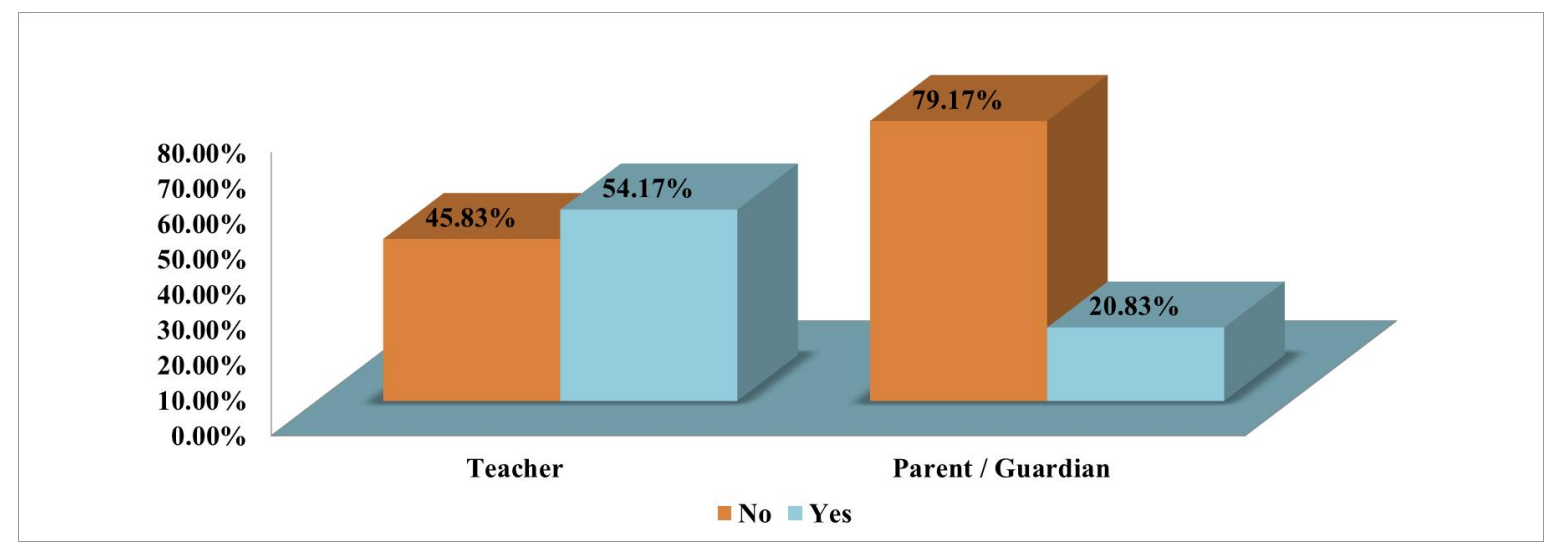

Graphic 4. Percentage of Teachers and Parent Who Have Taken Courses on Technology/Computer Source: own, from field studies conducted in the municipality of Ecatepec de Morelos, State of Mexico 
Only $20 \%$ teachers have taken courses the last 6 years and in the case of parents only $12.5 \%$ have taken courses in that period, as shown in Graphic 5.

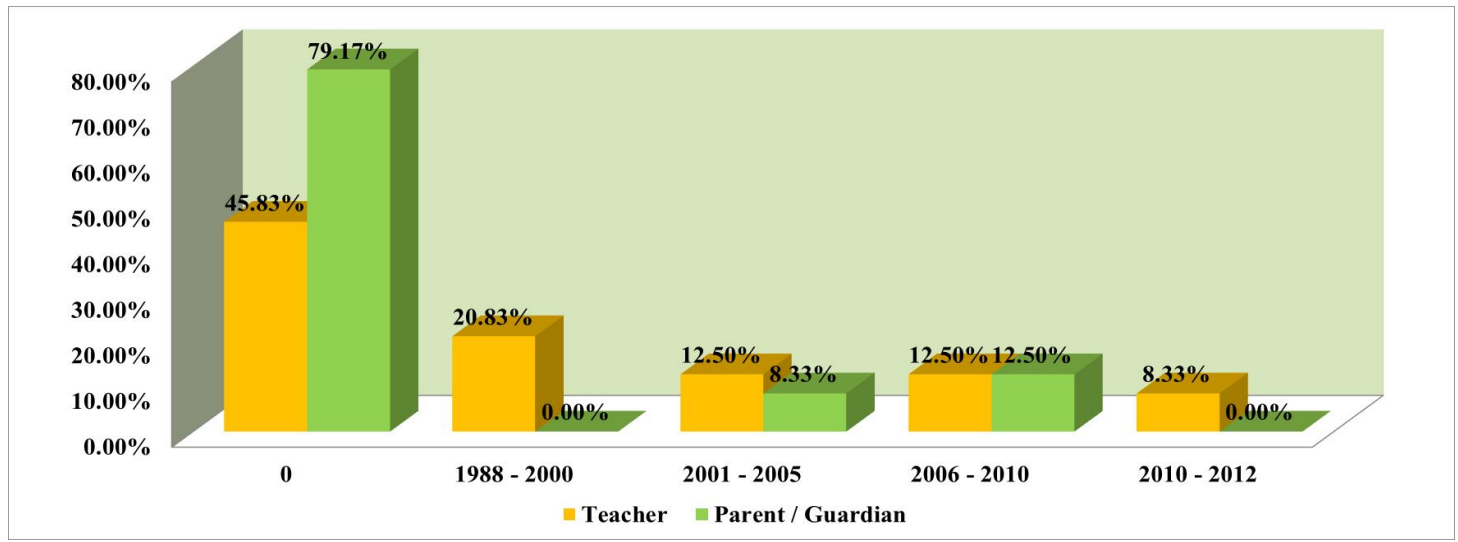

Graphic 5. Percentage of Teachers and Parent Who Have Taken Courses on Technology / Computer

Source: own, from field studies conducted in the municipality of Ecatepec de Morelos, State of Mexico

Is observed a deficit of $45.83 \%$ in taking computer courses for teachers, which is an important factor for the successful incorporation of information technologies, On the other hand, despite the remaining $54.17 \%$ of teachers have taken courses, only $20.83 \%$ have taken in the last 6 years. In this same indicator in the case of parents or guardians, it is evident the lack of training in computer courses, as only $20.83 \%$ has taken courses the last 6 years.

Lack of comprehensive proposals. This factor according to the author, has to do with the strengthening of the proposed technology, ie not only must present purely technological projects rather accompany the proposals of other factors that assist it the implementation correct of information systems, in this case it is recommended to accompany proposals for constant training and updated, well as involve indicators to control and correction of administrative and operational involving in the information systems

Integration of involved/feedback. This factor has to do with the feedback between the main actors that interact directly and indirectly with the successful implementation of information systems, since this type of feedbacks stimulate and enrich the academic performance of processes in public primary schools and therefore in the information systems that are incorporated in this sector, whatever the procedure is automated. It is therefore important that teachers, parents or guardians and staff, foster plannings and objective feedback.

Release of information. This factor is also part of the aspects that hinder the implementation of information systems, since it lacks the dissemination of information and even more if it comes to education and the processes involved, this lack of diffusion, limits the participation of those involved and hence the lack of knowledge in the use of technologies that are incorporated. Is presented in Graphic 6, the poor dissemination of information on the existence of information technology / information systems, the $29.17 \%$ of teachers indicated no knowledge of the existence of information systems, by other hand, the $70.83 \%$ of the parent indicated no knowledge of the existence of information systems.

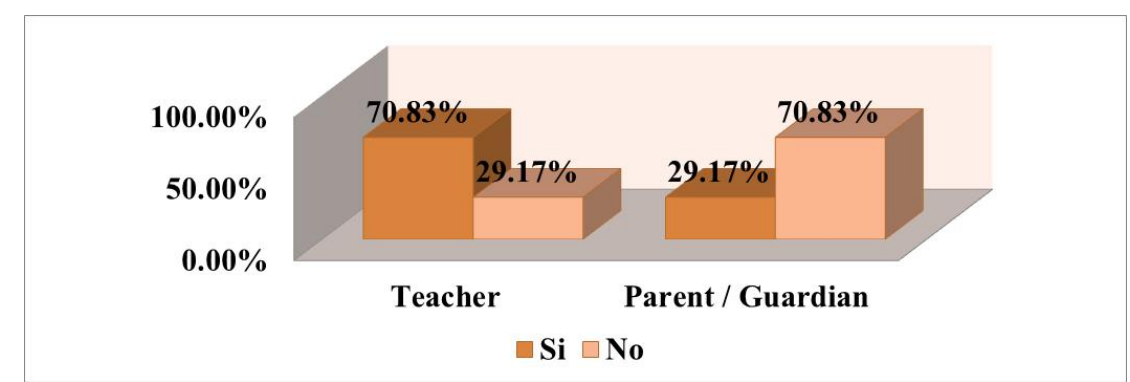

Graphic 6. Percentage of Teachers/Tutors Who Have Knowledge of the Existence of an Information System for Scholarly Information Query

Source: own, from field studies conducted in the municipality of Ecatepec de Morelos, State of Mexico 
Monitoring and evaluation process. This last factor is administrative, corrective and strategic nature, the author indicates that once the information system / information technology implemented should implement indicators to evaluate the functioning of the system, proper systematization of administrative processes and operational, and proposing corrective measures in case of deviations and finally, based on these indicators extend the functionality and scope of such systems

\section{Discussion/Conclusion}

Having identified the factors that impede the successful implementation of information systems, the proposed solution is presented below to assist in this implementation.

Initiation / Preparing the environment/Creation of indicators

- Initiation. Continue to search for administrative and operational processes that may be aided by information technology.

- Preparing the environment. Define the environment or place where the incorporation of information system is done correctly and lead through a department or responsible leadership

- Creation of indicators. From the initiation and preparation of the environment, create indicators that can measure certain technological and administrative/operational procedures to detect deviations and propose corrective measures

Contagion/Sensitization of innovation / Development of indicators

- Contagion. Promote the use of information systems to assist in the operational and administrative activities of public education.

- Sensitization of innovation. Behold the socialization of current topics that is awareness among the objectives sought with the use and implementation of information systems.

- Development of indicators. Continue the development of indicators to detect deviations and corrective measures.

Control / Exploring of technological resources/Measurement o the indicators.

- Control. This phase is critical to assess and identify omissions and errors in systematized processes, find the source and fix the problem.

- Exploring of technological resources. This phase should seek technologies that meet the needs of improvement opportunities, and currently have various alternatives of technologies as tools for the systematization of administrative and operational processes, at this stage should be find the advantages and disadvantages of each technology to select the ideal.

- Measurement o the indicators. Once in the earlier stages were designed the indicators, in this is proposed to start with the step of measuring of results, ie detect possible deviations and propose strategic measures. Without losing sight of the main objective

Integration / Exploration of educational resources / Measuring of the Results

- Integration. Call for an interaction between the actors of the administrative or operational process in which information systems are integrated in order to increase system functionality and improving operation.

- Exploration of educational resources. This phase is one of the most important as it has to do with the training of the people involved that make use of information systems and promote the increase in education levels, since they must train and prepare for the use of that technology to efficiently and effectively, to avoid underutilization of this in addition to promoting the creation of new ideas for improving the use of technology.

- Measuring of the Results. Continue with the detection of deviations or errors in the operation of the system or to identify improvements in procedures, depending on the indicators previously designed.

Information Management/Generating proposals and prototypes/Certifications and technological developments and increased functionality

- Information Management. Suggest new indicators that can assist in decision making and present strategies to continuously improve the efficiency of the system and the processes involved in it. 
- Generating proposals and prototypes. This phase aims to create proposals for the systematization of administrative and operational processes in public primary education. To ensure satisfactory implementation and in ongoing evolution.

- Certifications and technological developments and increased functionality. At this stage it is suggested that once it has made the creation, evaluation and implementation of strategies to improve opportunities for improvement from the indicators, begins with the certification process of the processes, in addition to providing technological developments with new versions, updates, and moreover, facilitate increased functionality within the information system, to continue the process of incorporation, development and improvement of the information systems.

Maturity / Feedback / Certifications, technological developments and increased functionality

- Maturity. It is important that the proposals can serve as support for education authorities at any level. Besides innovating with improvements in the system or creation of new information technologies, which aid them in continuous improvement of school management.

- Feedback. This part is from the point of view of the author, a central part and the interaction required between information systems and the operators thereof, to make suggestions for technology upgrades.

- Certifications, technological developments and increased functionality. Is suggesting further evaluation and implementation of strategies to improve opportunities for improvement based on the indicators. Start with the certification process and ultimately foster increased functionality within the information system.

The implementation of the proposed phases, at the suggestion of the author may vary, as this is adaptable to every situation, the importance lies in analyzing the needs and aim to be the incorporation of information systems, and of course its evolution and stay short, medium and long term, presented below in Figure 2, the proposal.

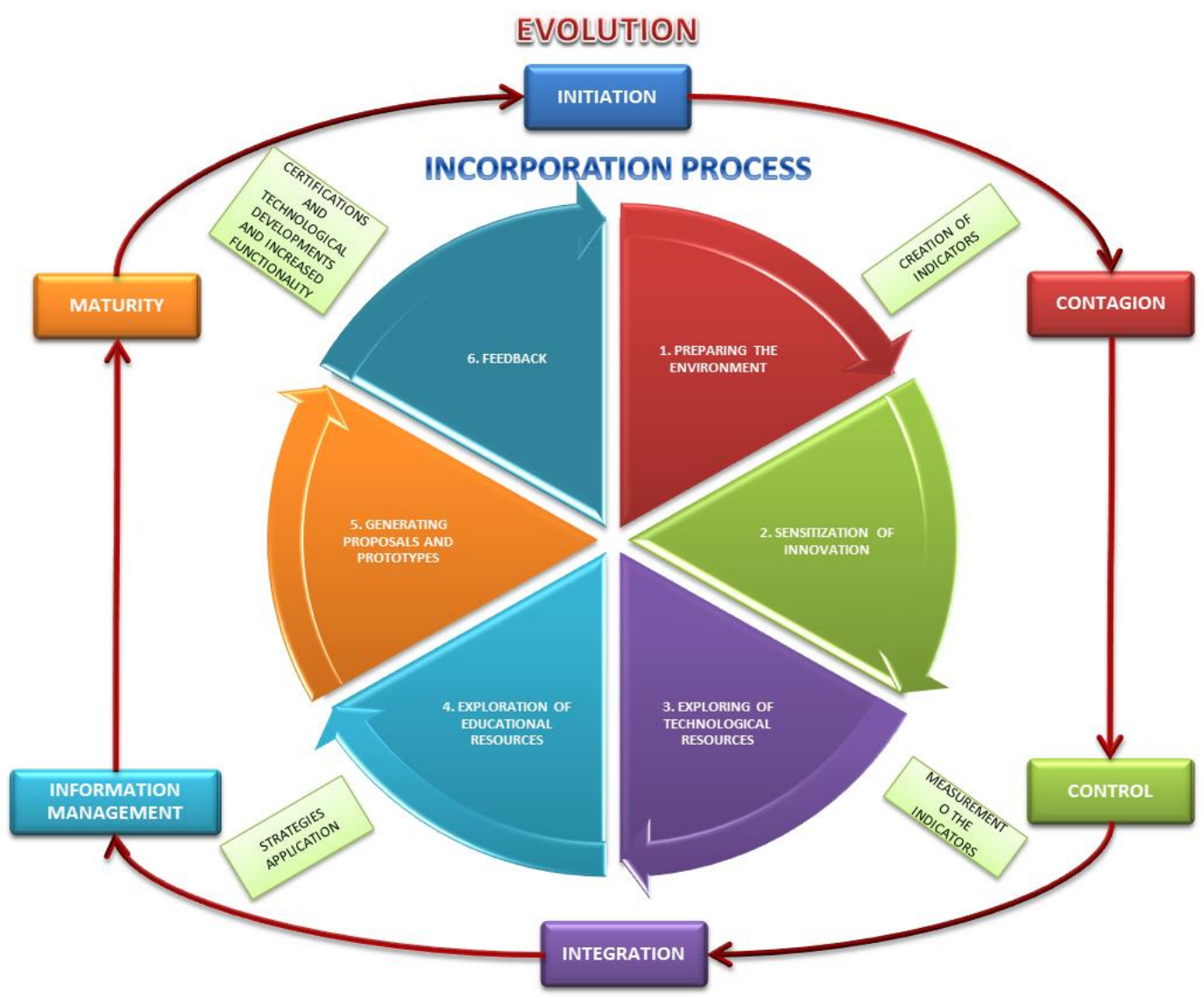

Figure 2. Proposal for the Successful Incorporation of Information Systems: The Case of Public Primary Education

Soucer: own adaptation, based on the evolution and integration of information systems Gibson \& Nolan (1974) y Montaño (2008), respectively. 


\section{References}

Andreu, R., \& Valor, J. (1991). Estrategia y Sistemas de Información(2nd edition). Madrid: Mc Graw-Hill.

Argyres, N. (1999). The Impact of information Technology on Coordination. USA: Organization Science.

Cámara de Diputados del H. Congreso de la Unión. (2010). Constitución Política de los Estados Unidos Mexicanos. México: DOF.

Castillo de la Peña. (2010). Metodología para la elaboración del trabajo científico (págs. 228 - 229). México: Instituto Politécnico Nacional.

Castrejon, J. (1986). Ensayos sobre política educativa. México: INAP.

Dyer, J., \& Nebeoka, K. (2000). Creating and Managing a High Performance Knowledge-Sharing Network. Strategic Management Journal, 21, 345-367.

Escalante, P. (1985). Educación e idieología en el México antiguo. México: SEP.

Fernández, Narez, \& García. (2008). Metodología de la investigación en ciencias sociales (págs. 54 - 58). México: Grupo Editorial Patria.

García, D. (2000). Sistemas de Información en la Empresa. Madrid: Pirámide.

Gibson, \& Nolan. (1974). Managing the four stages of EDP Growth (págs. 76-78). Estados Unidos de América: Harvard Business.

Hernández, R., Fernández, C., \& Baptista, P. (1997). Metodología de la investigación (1ra. Ed.). Colombia: McGraw Hill.

Iturriaga, J. (1981). La creación de la Secretaría de Educación Pública. México. México, FCE.

Laudon, K., \& Laundon, J. (1996). Administración de los Sistemas de Información. México: Prentice Hall.

Leenders, M., \& Wierenga, B. (2002). The Effectiveness of Different Mechanisms for Integrating Marketing and $R \& D$. USA: Journal of Product Innovation Management. http://dx.doi.org/10.1016/S0737-6782(02)00147-9

Lopez, I. (2007). La educación en México a través de los siglos. México: Universidad Vasco de Quiroga.

Martínez, A. (1992). La educación en el porfiriato. México: El Colegio de México.

Meneses, E. (1998). Un siglo de educación en México. México: FCE.

Monroy, G. (1975). Política educativa de la Revolución. México: SEP.

Montaño Váquez, V. (2008). Modelo de incorporación de TIC en el proceso de innovación. México: UNAM.

Ramos, M. (1973). Memoria sobre el estado de las provincias internas de Oriente. México: SEP.

Rangaswamy, A., \& Llien, G. (1997). Software Tools for New Product Development. Journal of Marketing Research, 34(1), 177-184. http://dx.doi.org/10.2307/3152074

Rotwell, R. (1994). Towards the Fifth Generation Innovation Process. International Marketing Review, 11(1), 7-31.

Song, X., Montoya, W., \& Schimidt, B. (1997). Antecedents and Consequences of Cross-Functional Cooperation. Journal of Product Innovation Management, 14(1), 35-47. http://dx.doi.org/10.1111/1540-5885.1410035 